\title{
Socio-Demographic Determinants of Adult Pulmonary Tuberculosis Patients: A Hospital Based Study at Dhanmondi, Dhaka, Bangladesh
}

\author{
Sadia Saber, Mohammad Monower Hossain
}

\section{ABSTRACT}

Background: Tuberculosis (TB) is a multi-system infectious disease with a major cause of morbidity and mortality all over the world but particularly in developing countries like Bangladesh. A normal healthy individual does not face the symptoms causing by tuberculosis due to their immune system that's why infection among healthy individuals always remain silent. As it is highly infectious air borne disease that's why treatment completion for TB is the cornerstone of its control and prevention. So to understand these factors efficiently this study was carried out about socio-demographic determinants of adult TB patients attending the tertiary care teaching hospital, Dhanmondi, Dhaka.

Methodology: This was hospital based cross sectional observational study done at Bangladesh Medical College Hospital, Dhanmondi, Dhaka with the study period from January 2020 to December 2021. Total 410 patients of age group 18 years and above with persistent cough with sputum production for more than 2 weeks were enrolled for this study purpose.

Results: Total prevalence of sputum positive adult pulmonary TB among the studied group was $69.02 \%$. Majority $54 \%$ were male patients in the age group of $41-50$ years $(31.45 \%)$. Pulmonary TB was predominantly diagnosed among employed group $41.34 \%$, those who have completed their high school level $(34.28 \%)$ in mainly the rural $(66.08 \%)$ locality. Joint family $(61 \%)$ with $8-10$ family members $(43.46 \%)$ have been found mostly affected in our study. The cardinal features were cough with sputum production $(80.21 \%)$ followed by fatigue $(71.73 \%)$, fever $(42.05 \%)$, sweating $(46.99 \%)$, loss of appetite $(32.86 \%)$ and weight loss $(27.56 \%)$. Pulmonary TB was found mostly among smokers $(57.23 \%)$ with normal BMI (44.88\%).

Conclusion: To decrease the rate of infection with Tuberculosis, a multifactorial approach can play the pivotal role by improving the living conditions, education level, economic status and adequate sanitation. Awareness can bring a new dimension in this regard.

Keywords: Socio-demographic determinants, tuberculosis.
Submitted : January 27, 2022

Published : February 23, 2022

ISSN: 2593-8339

DOI: $10.24018 /$ ejmed.2022.4.1.1223

S. Saber*

Department of Medicine, Bangladesh Medical College, Dhaka, Bangladesh.

(e-mail: sadiasaber201477@gmail.com) M. M. Hossain

Department of Medicine, Bangladesh Medical College Hospital, Dhaka, Bangladesh.

*Corresponding Author

\section{INTRODUCTION}

Tuberculosis (TB) is a multi-system communicable disease that is responsible for one of the major causes of morbidity and mortality all over the world mainly among developing countries. Among the 30 high TB-burden countries, Bangladesh is one of them. It accounts for $3.6 \%$ of the global totally. The estimated incidence of TB per 100,000 is 221 in Bangladesh, with a mortality rate of 24 per $1,00,000$ population [1]. About 64,000 people die solely due to TB in Bangladesh per year on average. Approximately $80 \%$ of all TB cases in Bangladesh are pulmonary TB [2]. The sociodemographic determinants may vary from country to country regarding TB. Among various determinants age is an important factor to stratify the risk of disease. The risk may increase in the elderly, possibly due to decrease in immunity status and presence of other co-morbidities. Active pulmonary TB bears some common clinical features like cough with sputum production with the presence of blood sometimes, weight loss, loss of appetite, fever, malaise, and night sweats [3]. The transmission of pulmonary TB is an active process because each individual with an active pulmonary TB can infect 10-15 individuals if they remain untreated [4]. Despite a lot of research and millions of dollars spending to uproot this disease, it is still able to contaminate the environment. Not only the medical treatment can concur this war, but we also need to give more focus on its early diagnosis and prevention as well. The aim of our study was to assess the main socio-demographic determinants of adult pulmonary TB patients seeking treatment from tertiary care teaching hospital, Dhanmondi, Dhaka. 


\section{MATERIALS AND Methods}

\section{A. Study Design \& Area}

This is a population based cross sectional observational study carried out in both indoor and outdoor Medicine department of Bangladesh Medical College (BMCH), Dhanmondi, Bangladesh.

\section{B. Study Period}

The study was conducted from January 2020 - December 2021.

\section{Study Population}

All the cases of confirmed Pulmonary TB were included here as the study population fulfilling the inclusion and exclusion criteria. After the diagnosis, the patients were interviewed immediately and enrolled in our study until the sample size was achieved.

\section{Inclusion Criteria}

- Confirmed diagnosis of pulmonary TB on the basis of sputum smear, and gene $\mathrm{X}$ pert reports.

- Age 18 years and above

- Informed written consent

\section{E. Exclusion Criteria}

- Pregnant woman

- Patients not willing to participate in the study

- Previous history of pulmonary or extra-pulmonary TB

- Alteration in higher psychic function in critically ill patients.

\section{F. Sampling Techniques}

Consecutive convenient (purposive) sampling method was applied in here.

\section{G. Data Collection}

All the subjects underwent medical history assessment, general clinical examination before enrolment. Patients provided the informed consent before they participated in the study. Once informed consent was obtained, all participants were asked to complete a questionnaire to collect basic demographic information such as age, gender, height, weight, educational level, number of family members living together, employment status, average income in the family, area of residence and smoking history.

Here, we have calculated the BMI from the height and weight of the patients to categorise them more effectively according to the nutritional status.

All the study participants visited to $\mathrm{BMCH}$ with various symptoms like cough with productive sputum for more than 2 weeks, fever, malaise, weight loss, loss of appetite underwent investigations to enable appropriate disease diagnosis.

\section{H. Data Analysis}

Data was recorded into semi-structured pre-tested pro forma. It was entered into Microsoft Excel and analysed using SPSS v 16.0. Summarisation of data was done according to data types and appropriate statistical tests were done. The various modes of clinical presentation were expressed as the total number of patients presenting with a particular presenting feature and then calculated as a percentage of the total number of patients. Statistical analysis was done by using appropriate statistical tool like 'chi-square' test, student ' $t$ ' test, where applicable. A p-value of $<0.05$ was considered to be statistically significant and p-value of $>0.05$ was considered not significant statistically.

Informed consent was taken in all the cases and the records were kept confidentially.

\section{Ethical Clearance and Informed Consent:}

The study was carried out after obtaining approval from the Institutional Ethical Committee. The participants were briefed about the purpose of the study and informed consent was obtained prior to the data collection.

\section{RESUlts}

\section{A. Total Prevalence of Pulmonary TB among the Studied Respondents}

Among 410 study population sputum was found positive in 283 patients and others $(30.98 \%)$ were not able to detect. (Table I).

\begin{tabular}{ccc}
\multicolumn{3}{c}{ TABLE I: PREVALENCE OF PULMONARY TB AMONG STUDY } \\
& POPULATION & \\
\hline \hline Sputum Findings & Number of & Percentage(\%) \\
(Mycobacterium & Patients (n) & \\
tuberculosis) & 283 & $69.02 \%$ \\
\hline \hline Detected & 127 & $30.98 \%$ \\
Not detected & 410 & $100 \%$ \\
Total &
\end{tabular}

\section{B. Age and Gender Wise Distribution of Study Group}

Among 283 sputum positive patients majority (54\%) were male patients (Fig.1).

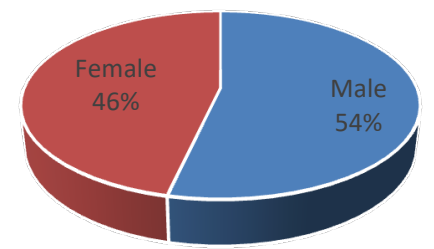

Fig. 1. Gender wise distribution of study group.

Majority (31.45\%) of the sputum positive TB patients were in the age group of $41-50$ years followed by $20.14 \%$ were in the 51-60 years' category. It was proven statistically significant in our study $(\mathrm{p}<0.004)$. Interestingly, majority $(26.83 \%)$ of the sputum negative patients were also at the age group of 41-50 years (Table II).

TABLE II: AGE WISE DISTRIBUTION OF STUDY GROUP

\begin{tabular}{|c|c|c|c|c|c|}
\hline Age & Sputum positive & Percentage $\mathrm{S}_{1}$ & Sputum negative & Percentage & Total $(\%)$ \\
\hline $20-30$ & 39 & 13.79 & 19 & 14.97 & $58(14.14)$ \\
\hline $31-40$ & 43 & 15.19 & 23 & 18.11 & $66(16.097)$ \\
\hline $41-50$ & 89 & 31.45 & 21 & 16.54 & $110(26.83)$ \\
\hline $51-60$ & 57 & 20.14 & 33 & 25.98 & $90(21.95)$ \\
\hline$>60$ & 55 & 19.43 & 31 & 24.41 & $86(20.98)$ \\
\hline Total & 283 & 100 & 127 & 100 & $410(100)$ \\
\hline
\end{tabular}




\section{Family Type, Size and Annual Income among Study Group}

In our study most $(61.13 \%)$ of the TB patients belonged from the joint family with the number of family members 8 $10(43.46 \%) .38 .52 \%$ TB patients had an annual family income ranged from 51,000-1,00,000 Bangladeshi taka (Fig. $2,3,4)$.

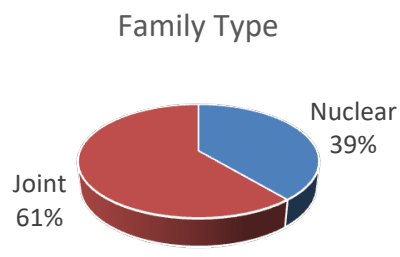

Fig. 2. Types of family among study group.

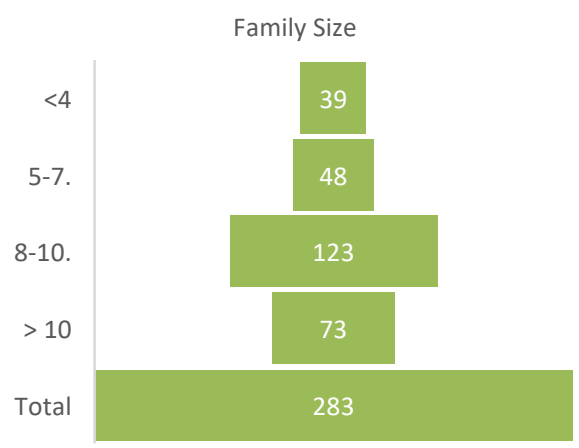

Fig. 3. Family size among TB patients.

Annual Income(Bangladeshi Taka)

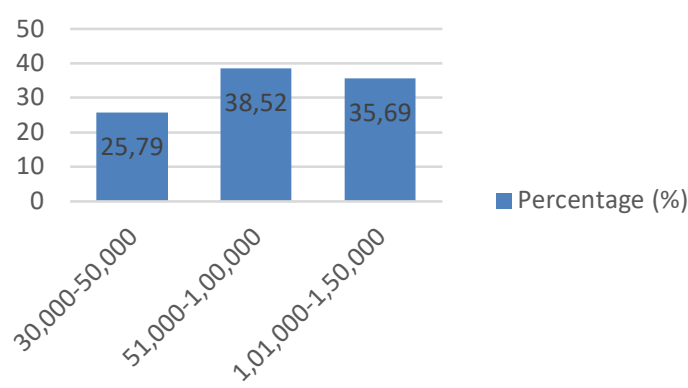

Fig. 4. Annual family income among study group.

\section{Area of Residence of Study Population}

Most of our Pulmonary TB patients belonged from rural areas $(66.08 \%)$ in comparison to the urban areas $(33.92 \%)$ which was not found statistically significant here $(\mathrm{p}<0.324)$. (Fig. 5).

\section{Area of Residence}

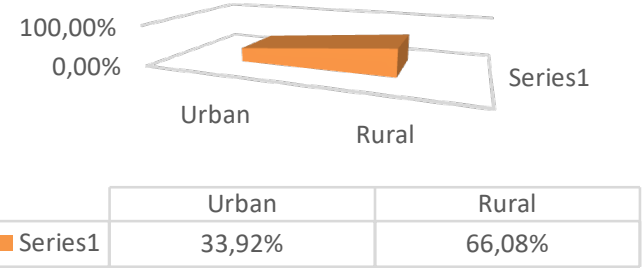

Fig. 5. Area of residence of study group.

\section{E. Level of Education and Employment Status among TB Patients}

In our study $34.28 \%$ TB patients had completed their high school and $41.34 \%$ found to be employed. Although these findings were not proven statistically significant here $(\mathrm{p}<0.343)$ (Table III, IV).

\begin{tabular}{ccc}
\multicolumn{2}{c}{ TABLE III: LEVEL OF EDUCATION AMONG TB PATIENTS } \\
\hline \hline Level of Education & No of patients (n) & Percentage (\%) \\
\hline \hline None & 28 & 9.89 \\
Primary & 83 & 29.33 \\
High School & 97 & 34.28 \\
University & 75 & 26.5 \\
Total & 283 & 100 \\
\hline \hline
\end{tabular}

\begin{tabular}{ccc}
\multicolumn{2}{c}{ TABLE IV: EMPLOYMENT STATUS OF THE STUDY GROUP } \\
\hline \hline Employment Status & No of Patients(n) & Percentage (\%) \\
\hline \hline Employed & 117 & 41.34 \\
Unemployed & 76 & 26.86 \\
Retired & 47 & 16.61 \\
Student & 43 & 15.19 \\
Total & 283 & 100 \\
\hline \hline
\end{tabular}

\section{F. Social Habits among Study Population}

During analysing of the social habits male smokers $(57.23 \%)$ were found to be predominant. Very few $(2.12 \%)$ Alcoholic people were found in our study population. Rest are non-smokers $(59.36 \%)$ among which mainly are females (Table V).

\begin{tabular}{cccccc}
\multicolumn{7}{c}{ TABLE V: SOCIAL HABITS ANALYSIS } \\
\hline \hline Social Habits & Male & $\begin{array}{c}\text { Percentage } \\
(\%)\end{array}$ & Female & $\begin{array}{c}\text { Percentage } \\
(\%)\end{array}$ & $\begin{array}{c}\text { Total } \\
(\text { Percentage) }\end{array}$ \\
\hline \hline Smokers & 87 & 57.23 & 22 & 16.79 & $109(38.51)$ \\
Alcoholic & 6 & 3.95 & 0 & 0 & $6(2.12)$ \\
Non smokers & 59 & 38.82 & 109 & 83.21 & $168(59.36)$ \\
Total & 152 & 100 & 131 & 100 & $283(100)$ \\
\hline \hline
\end{tabular}

\section{G. Distribution of Study Subjects according to BMI}

$44.88 \%$ study subjects were found to be in the normal range of BMI whether as $33.92 \%$ belonged to underweight. Only 6\% subjects were found obese in our study (Fig. 6).

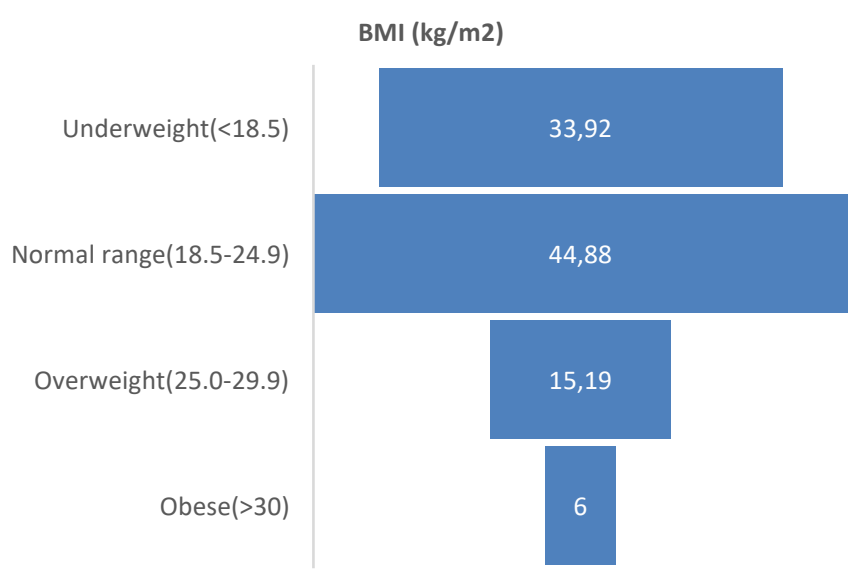

Fig. 6. Distribution of study subjects according to BMI. 


\section{H. Various Clinical Presentation among Study Group}

Among various clinical presentations cough with expectoration $(80.21 \%)$ belonged to one of the main symptoms in our study. There were many variations among presentations of other features like fever $(42.05 \%)$, fatigue $(71.73 \%)$, loss of appetite $(32.86 \%)$ and weight loss $(27.56 \%)$. Small number of patients $(2.12 \%)$ complained about chest pain (Fig. 7).

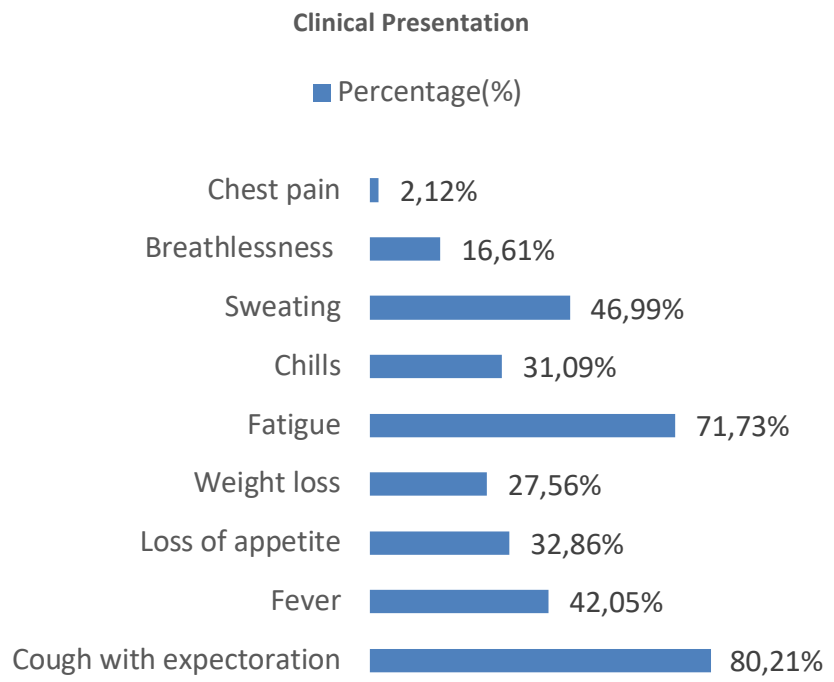

Fig. 7. Various clinical presentation among study group.

\section{Discussion}

In our present study maximum study subjects were found to be males $(54 \%)$ compared to females $(46 \%)$. Similar findings of male predominant pulmonary TB were found in various studies of different countries. $57.8 \%$ male vs $42.2 \%$ female with positive pulmonary TB was found in one study conducted by [5]. Another study found the percentage $66 \%$ vs $34 \%$ among males and females with same condition [6]. But neither the present not the past studies found this male predominant positive pulmonary TB cases statistically significant.

In the present study majority of the study population (31.45\%) belong to age group 41-50 years bearing the 2 nd majority group (20.14\%) 51-60 years. It implies that age is an important factor here probably due to decrease immunity along with the ageing process leading to the development of more pulmonary TB cases.

The study shows that $61 \%$ joint family members came with positive pulmonary $\mathrm{TB}$ in comparison to $39 \%$ nuclear families. Although the number of family members also play a role in our study where $43.46 \%$ cases had 8-10 members living together with an annual income ranging from 50,0001,00,000 Bangladeshi taka (38.52\%). Socio-economic status and living conditions have always got a great impact in the pathophysiology of this disease process. It predominates on the overcrowding situation which can be clearly visible from our findings. Similar findings has also observed by [7], [8], they found sputum positive pulmonary TB among $44.2 \%$ cases but they have not found any statistical significance whether as we found our findings statistically significant with $\mathrm{p}$ value $<0.003$.

Cigarette smoking is associated with damage to the lung parenchyma and decrease the immune response that's why people may predispose to various respiratory insults. Mycobacterium tuberculosis is one of these insults that can grow very rapidly in such circumstances. Probably due to this we found that $57.23 \%$ of our study group members were smokers. Similar findings have also been observed in various studies. One study found that $50 \%$ of their study population were smokers and they put it as one of the main factors for the development of pulmonary TB [9]. Alcohol can also put negative effects on the immune system and the treatment of pulmonary TB patients but very few $2.12 \%$ cases were alcoholic in our study that's why we couldn't be able to evaluate this factor.

Education is an important factor in the prevention of TB as it can create awareness among people regarding its transmission and importance of treatment continuation. Though there was not that much variation of educational level was found in our study. $41.34 \%$ employed persons were found TB positive in here, which has got some similarities with findings found in one study done in [10].

In our present study cough with expectoration (80.21\%) was the predominant clinical feature followed by fatigue $(71.73 \%)$ and fever $(42.05 \%)$. Patients presented with cough with sputum for more than 2 weeks along with other clinical features mainly chosen primarily for our study population. Similar observations were also seen in many studies among which [11] mentioned cough with expectoration as their main presentation. Weight loss $(27.56 \%)$ was not that much predominant in our study which has got some similarities with [8] where they have reported $30.32 \%$ cases of weight loss among TB patients.

\section{CONCLUSION}

Bangladesh has got high level of complexity in the public health dimensions as a result multiple risk factors play an important role in the pathogenesis of not only Tuberculosis but also many chronic infectious diseases. Based on our findings of family size, number of family members, socioeconomic status, educational level and smoking habit have secured top position among adult pulmonary TB patients. But these factors can be modified by proper education, sanitation, and nutritional requirements. We have to create awareness among people regarding its prevention and treatment continuation otherwise the number of TB patients and its complexity will be very difficult to control in the near future that can result into high number of cases with morbidity and mortality.

\section{LIMITATIONS}

As the current study has carried out in a tertiary care teaching hospital in the urban area, hence the results may not be the complete reflection of the Pulmonary TB cases in whole community. More studies need to be accomplished to bring a definitive conclusion in this communicable disease. Moreover, only some specific variables of interest have taken for observation in our study. 


\section{ACKNOWLEDGMENT}

The authors wish to thank the Ethical Committee of Bangladesh Medical College for approving and providing the opportunities to complete the research work and grateful to the Microbiology laboratory staff for their help during this study. The authors also acknowledge the cooperation of the patients who participated in this study.

\section{REFERENCES}

[1] World Health Organization. Global Tuberculosis Report. Geneva: World Health Organization. 2020.

[2] World Health Organization. Global Tuberculosis Report. Geneva: World Health Organization. 2018.

[3] Herzog H, Basil M. History of tuberculosis. Respiration. 1998; 65: 79.

[4] Ministry of Health and Family Welfare. Estimated Global Inci- dence. RNTCP status report 2011.

[5] Kaulagekar A, Radkar A. Social Status Makes A Difference: Tuberculosis Scenario During National Family Health Survey-2. Indian J Tuberc. 2007; 54(1): 17-23.

[6] Baburao P, Bhaskar P, Deepak P, Sharma YV. Study of Tubercu- losis cases under RNTCP attending Designated Microscopy Centre at Pravara Rural Hospital, Loni. Pravara Med Rev. 2009; 4(4): 7-11.

[7] Khan QH. Epidemiology of Pulmonary tuberculosis in Rural Aligarh. Indian Journal of Community Medicine. 2006; 31(1): 39- 40.

[8] Jha A. An Epidemiological Study of Pulmonary Tuberculosis in the Field Practice Areas. 2010.

[9] Noertjojo K, Tam CM, Chan SL, Chan-Yeung MM. Extra-pulmonary and pulmonary tuberculosis in Hong Kong. International Journal of Tuberculosis Lung Disease. 2002; 6(10): 879-886.

[10] Steffen R, Menzies D, Oxlade O, Pinto M, de Castro AZ, Monteiro P, et al. Patients' costs and cost-effec- tiveness of tuberculosis treatment in DOTS and Non-DOTS Facilities in Rio de Janeiro, Brazil. PLoS One. 2010; 5(11): e14014.

[11] Othman GQ, Ibrahim MIM, Raja YAA. Comparison of the clinical and socio-demographical factors in pul- monary and extra pulmonary tuberculosis patients in Yemen. Journal of Clinical and Diagnostic Research. 2011; 5(2): 191-195. 